www.jmscr.igmpublication.org

Impact Factor (SJIF): 6.379

Index Copernicus Value: 71.58

ISSN (e)-2347-176x ISSN (p) 2455-0450

crossref DOI:_https://dx.doi.org/10.18535/jmscr/v6i4.79

Journal Of Medical Science And Clinical Research

IGM Publication

An Official Publication of IGM Publication

\title{
Perception of First Year MBBS Students on Self-Directed Learning in Anatomy: Improves Concept, Retention and Communication skills
}

\author{
Authors \\ Anita R Gune ${ }^{1}$, Swati S More ${ }^{2}$, Supriya P Satpue ${ }^{3}$, Dhanaji T Wagh ${ }^{4}$, \\ Vasudha R Nikam ${ }^{5}$ \\ ${ }^{1}$ MS Anatomy, Associate Professor, Dept. of Anatomy, D.Y. Patil Medical College, Kolhapur \\ ${ }^{2,2,4}$ MSc Anatomy, Tutor, Dept of Anatomy, D.Y. Patil Medical College, Kolhapur \\ ${ }^{5}$ MS Anatomy, Professor and HOD, Dept. of Anatomy, D. Y. Patil Medical College, Kolhapur \\ Corresponding Author
}

Anita Rahul Gune

Associate Professor, Dept. of Anatomy, D.Y. Patil Medical College, Kolhapur, Maharashtra, India-416006

Email: anitargune@gmail.com

\begin{abstract}
Introduction: As anatomy subject is the basis of all surgical branches, its understanding in depth is of great value. Surgeons need to understand normal morphology of organs to understand the Pathology. Syllabus of Anatomy is vast and also volatile, to summarise large amounts of facts and train students for acquisition of skills, we believes that student learn by practice.

Aims and Objectives: To help students for development of concepts, to assess the student's opinion about Self-Directed Learning (SDL) method and to evaluate retention of subject.

Method: The present study included 140 students of first year MBBS. Steps to conduct SDL were four. Orientation and planning, Brain storming session, Presentation and Written Assessments. Total 10 close ended feedback questionnaires were given after SDL intervention.

Results: It was observed that students enjoyed the new method of teaching and they felt that it could be helpful to perform better in university examination. At the same time student's perception was assessed by using Pre and Post Multiple Choice Questions test (MCQ). All the students scored better in the post-test, hence making it evident as to how helpful this session had been, to clear the concepts. Students wrote the answers to the point with well labelled diagram and presented the answers in a proper manner.

Conclusion: SDL definitely improved understanding of the subject. This method encourages students to actively participate leading to active learning with better retention, in additionthismethod helped students to develop communication skills.
\end{abstract}

Keywords: Self-Directed Learning, Medical Students, Innovative teaching method.

\section{Introduction}

Education in medical profession is been concentrated since past 10 years ${ }^{(1)}$ This educational approach emphasizes active participation by students in order to develop motivation, autonomy and self-interest in the learning process ${ }^{(2)}$

To achieve knowledge, active involvement of the student and teacher helps the course to be enjoyable 
and definitely helps for integration. Students are responsible for their own learning process, thus avoiding a passive attitude to the lectures. It is need of the time to formulate process of learning as best to demand from the students ${ }^{(3)}$

Pre-clinical that is first year of M.B.B.S course relates to basis of all clinical subjects. Regular didactic lectures are teacher centred, with minimal participation from the students. Due to this traditional method creating interest and also motivating thinking abilities of the students is not achieved $^{(4)}$

Nowadays different innovative teaching methods with focus on students which inculcate selflearning directed. These methods have more retention and knowledge of the subject ${ }^{(5)}$

As anatomy subject is the basis of all surgical branches, its understanding in depth is of great value. Surgeons need to understand normal morphology of organs to understand the Pathology. Syllabus of Anatomy is vast and also volatile, to summarise large amounts of facts and train students for acquisition of skills, we believes that student learn by practice. Practice means to perform over and over again in the face of obstacles. Practice means of inviting perfection desired. With the objective to check students understanding and knowledge on the topic, 'ARCHES OF FOOT' Selfdirected learning (SDL) is considered. The main aim of this concept is to enhance teaching pattern and make learning and teaching an enriching experience. This session definitely will help students to prepare for formative and summative, so that students perform it without any hesitation.

\section{Materials and Methods}

The main objectives of present study were:

- To help students for development of concepts

- To assess the student's opinion about SDL method

- To evaluate retention of subject

The present study was conducted by the department of Anatomy during academic year 2017 to 2018 .
The study was approved by institutional ethical committee.

Steps to conduct SDL were four

Step 1: Orientation and planning

In session Specific Learning Objectives was decided, allotment of groups were decided, list of reference books were made. Methodology of conducting brain storming session, presentation session and theory assessment session was planned for execution. As students were 150 and facilitator were four, we divided 150 students into 4 groups. In the Selfdirected learning session, the class was divided into 4 sub-batches.

Step 2: Brain storming session

In brain storming session was conducted on same day. Batch was divided into groups with an average of around 6 students per group by students as per their choice. Each batch had 5 groups. Every batch had a facilitator faculty. Each group had a Leader, resource person, communicator, creativity in charge, record keeper and a coordinator. The students were given adequate time to thoroughly prepare the topic. During this period leaders of each group was in constant communication with the batch facilitator and his group also.

Step 3: Presentation

For Presentation session which was conducted after 20 days, present number of students were 140 out of 150. Each group was given about 15 minutes to present the topic to the fellow students in the audience, under the invigilation of the respective facilitator. Elaborate charts and models were prepared by every group as pictorial description is important for quick learning. Some students also performed short skits to explain the overall clinical aspects of Arches of foot.

Each batch was assess by the Facilitator according to Assessment Sheet. The heading in sheet were: Subject, Narrative skills, Participation, Aids, and Time. Each heading was allotted 5 marks so total was 25 marks

Multiple Choice Questions (MCQ) tests were taken before and after this interactive session. MCQs were decided by all the four facilitators and was validated by department. 


\section{JMSCR Vol||06||Issue||04||Page 478-482||April}

Step 4: Written Assessments

The last phase of this SDL, Assessment was taken after 15 days of step 3. It was theory test in which students were asked to write a Long Answer Question on "Medial Longitudinal Arch", Theory assessment was calculated from 10 marks.

\section{Statistical Analysis}

All the results were expressed as mean \pm S.D. Students paired and unpaired ' $t$ ' test was to analyse the data. $\mathrm{P}$ valve less than 0.05 was considered significant. $\mathrm{P}$ valve was highly significant. The statistical analysis was done by using SPSS, version 23.

\section{Results}

Total 10 close ended feedback questionnaires were given after SDL intervention. It was observed that students enjoyed the new method of teaching and they felt that it could be helpful to perform better in university examination (99.30\%), as seen in Chart: 1, Students developed interest in the subject. Chart: 1 shows student's perception on SDL method $(n=140)$.

Chart 1: Feedback Analysis

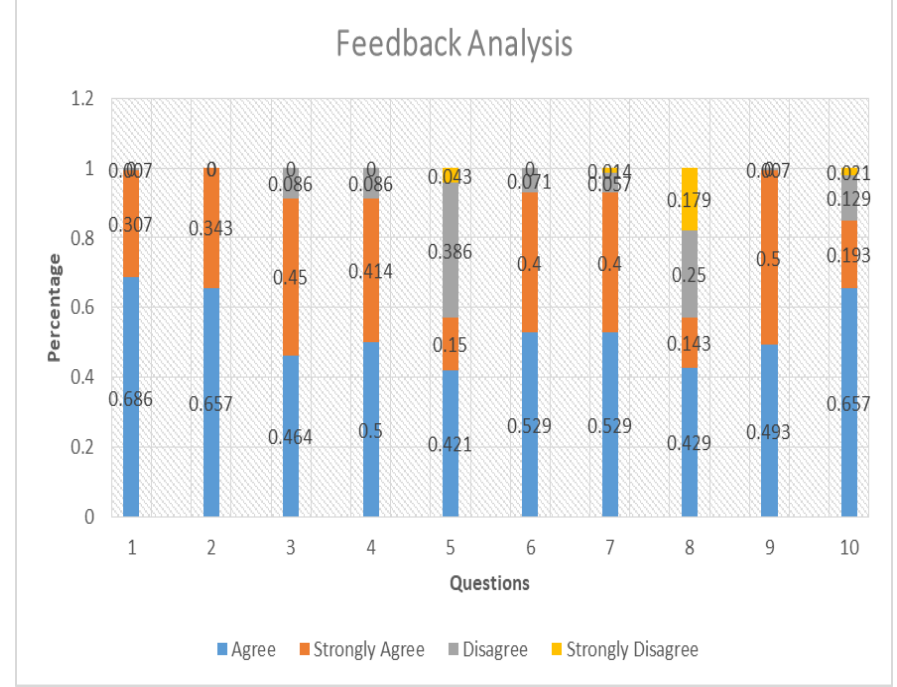

Questions in Feedback Form

1. Method used in teaching (SDL) in Anatomy was useful and developed interest in subject

2. SDL helped in improving understanding further

3. This method aroused curiosity about the topic and generated lot of new ideas
4. This method helped interactive discussion in the groups

5. SDL is superior to regular lectures

6. SDL was conducted in a systematic manner

7. Facilitator was very helpful for smooth conduction

8. SDL was time consuming

9. SDL will be helpful to perform better in university Examination

10. I found the method to be good for clearing doubts which I had after the traditional lecture

At the same time student's knowledge was assessed by using Pre-test MCQs and Post -test MCQs (Chart: 2). It was noted that post-test score (7.32 \pm 1.54) was increased than that of pre-test score $(5.95$ \pm 1.76 ). All the students scored better in the posttest, hence making it evident as to how helpful this session had been, to clear the concepts.

\section{Chart 2: Pre-test and Post Test MCQ}

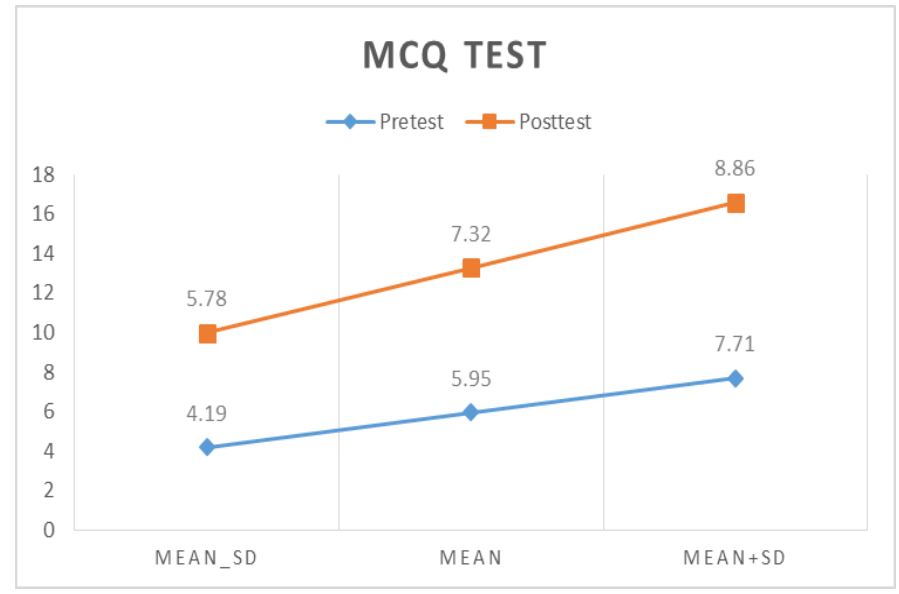

In step 3 -presentation session, Groups scored marks ranging from 13 to 22 as shown in Table: 1 . Students put in full effort to secure good marks and it aroused a healthy competition among the students Lastly in step 4, Students wrote the answers to the point with well labelled diagram and presented the answers in a proper manner. Students performed well with marks ranging from 5 to 9 out of 10 marks. 
Table 1: Presentation session

\begin{tabular}{|l|c|c|c|c|c|c|}
\hline $\begin{array}{l}\text { Gro } \\
\text { up }\end{array}$ & $\begin{array}{c}\text { Subje } \\
\text { ct }\end{array}$ & $\begin{array}{c}\text { Narrati } \\
\text { ve } \\
\text { skills }\end{array}$ & $\begin{array}{c}\text { Participatio } \\
n\end{array}$ & Aids & Time & Total \\
\hline A1 & 5 & 5 & 5 marks & 5 & 5 & 25 \\
\hline A2 & 4 & 4 & 3 & 3 & 3 & 15 \\
\hline A3 & 3 & 2 & 3 & 3 & 4 & 18 \\
\hline A4 & 3 & 3 & 2 & 2 & 3 & 14 \\
\hline A5 & 3 & 2 & 2 & 3 & 4 & 13 \\
\hline B1 & 3 & 4 & 3 & 4 & 3 & 17 \\
\hline B2 & 3 & 2 & 2 & 3 & 4 & 14 \\
\hline B3 & 4 & 4 & 4 & 5 & 4 & 21 \\
\hline B4 & 4 & 4 & 3 & 3 & 4 & 18 \\
\hline B5 & 3 & 3 & 3 & 3 & 3 & 15 \\
\hline C1 & 4 & 4 & 4 & 4 & 4 & 20 \\
\hline C2 & 4 & 4 & 4 & 4 & 3 & 19 \\
\hline C3 & 3 & 3 & 4 & 3 & 3 & 16 \\
\hline C4 & 3 & 4 & 4 & 3 & 3 & 17 \\
\hline C5 & 3 & 3 & 4 & 1 & 2 & 13 \\
\hline D1 & 3 & 3 & 3 & 3 & 4 & 16 \\
\hline D2 & 4.5 & 4 & 4.5 & 4.5 & 4.5 & 22 \\
\hline D3 & 3 & 3.5 & 3 & 3 & 3 & 17.5 \\
\hline D4 & 2.5 & 2.5 & 3 & 3 & 4 & 15 \\
\hline D5 & 4 & 3 & 4.5 & 3 & 4 & 20 \\
\hline & & & & & 3 & \\
\hline
\end{tabular}

\section{Discussion}

Anatomy is one of the basic subject essential for a medical curriculum. In the syllabus of Anatomy, we as anatomist have to teach gross, histology as well as embryology. It is important that students have to gasp information about anatomy to apply it in clinical medicine ${ }^{(6)}$ Faculty members working with students must cope with additional demands to provide quality cooperative teaching. Unfortunately, success in passing exams remains the major driving force for institutions and students alike, instead of actual learning.

SDL is time consuming method of learning, in our study $57.20 \%$ students agree to this as shown in chart: 1. But once faculty and students get use to this method of teaching and learning, this will definitely improve understanding of the subject. SDL helps to clear doubts, perform better in examination.

Moreover, this method encourages students to actively participate leading to active learning with better recall as prove in our study by assessed them theoretically after 15 days without prior intimation. Definitely students performed well with marks ranging from 5 to 9 out of 10 marks. Additional benefits of this method was it helped students to develop communication skills. We did appreciate their efforts in step 3 as shown in Table 1. In such teaching methodology group discussion also serves to provide an additional means of study as well as for preparing students for future similar discussions considering various topics.

\section{Conclusion}

SDL is innovative method to teach Anatomy. This method definitely improve understanding of the subject. It also helps the students to clear doubts, perform better in examination. This method encourages students to actively participate leading to active learning with better retention. Additional benefits of this method was it helped students to develop communication skills. In various steps of SDL group formation, group discussions makes students association with each other better.

\section{Acknowledgement}

The researcher would like to express her obligation to faculty of Department of anatomy for their help to conduct this session. Special thanks to Dr. D.T. Wagh and Dr. Supriya Satpute for being facilitators for conducting SDL.

\section{References}

1. Kedar. B. Joshi, Anup N. Nilawarand A. P. Thorat. Effect of case based learning in understanding clinical biochemistry. IJBAR2014; 5(10):516-518.

2. Vaishali P, Sunita T, Praveen I, N Venugopal, Chaitanya K,Amruta K. A Study of Perception of First Year MBBS Students on Case-Based Learning in Biochemistry. Natl J Integr Res Med 2017; 8(5):67-70

3. Saville B, Zinn T, Neef N, Van Norman R, Ferreri S. A comparison of inter-teaching and lecture in the college classroom. Journal of Applied Behavior Analysis. 2006; 39:4961.

4. Somnath T. Salgar. Case based learning: an innovative student-centred methodology for teaching biochemistry. IJBAR2014; 5(1):2527. 
5. Sandhya Pillai Nair, Trushna Shah, Shruti Seth, Niraj Pandit, G.V. Shah. Case Based Learning: A Method for Better Understanding of Biochemistry in Medical Students. Journal of Clinical and Diagnostic Research. 2013 Aug; 7(8): 1576-1578.

6. P. Marcos, M.M. Arroyo-Jiménez, E. Artacho-Perula, A. Martínez-Marcos,X. Blaizot, M.T. Alfonso-Roca, L. Branda and R. Insausti. Self-directed learning in the Gross Anatomy medical curriculum. Eur J Anat, 8 (3): 147-153 (2004). 